\title{
Numerical and Experimental Evaluation of New Cold form Inverted "U” Section in Single or Multiple Family Dwellings' Flooring Systems
}

\author{
Amin Ghafooripour ${ }^{1}$ and Connor Pearson ${ }^{2}$ \\ 1. Department of Civil Engineering, Santa Clara University, Santa Clara, CA 95053, USA \\ 2. School of Engineering, Santa Clara University, Santa Clara, CA 95053, USA
}

\begin{abstract}
This article will introduce a new version of the metal deck for building residential flooring with a newly designed cold form U section. This flooring will allow residential structures to be built more quickly while also reducing the necessary thickness of the floor. The level of strength and deflection of this floor will be determined via analysis of a floor bed comprised of cold-formed inverted U sections (IUS) covered by sheathing that is subjected to different loading scenarios. The necessary computational quantities associated with the experiment have been compared to established laboratory values by performing all related and applicable tests. Then, these quantities are compared to different existing flooring techniques to determine the efficacy of this technique. The results show that this flooring technique can be effective and cost-efficient in residential applications.
\end{abstract}

Key words: IUS, sheathing, metal deck, U section, experimental test.

\section{Introduction}

Today, most roofs are built with the building materials available in the area in mind. For many western countries, including the United States, most of the flooring in residential structures is primarily made from wood. The metal deck is also commonly found in modern structures, but it is usually too expensive for single or multiple-family dwellings. However, by utilizing a new technique, it is possible to create flooring suited for residential buildings that combine the benefits of wood and metal deck.

Wood is often viewed as a preferable residential building material due to its relative abundance and ability to be cut and shaped easily. Wood beams are also cheap when compared to other building methods and do not require advanced machinery to install (Fig. 1). Wood joists, which are made by surrounding a

Corresponding author: Amin Ghafooripour, Ph.D., adjunct professor, research fields: structural engineering; vibrations, dynamics, vibrations. plywood center with wood flanges in an I-shape, are also commonly used [1]. These joists provide a lightweight and reliable alternative to sawn lumber but typically cost more to produce than traditional wood beams (Fig. 2). However, large amounts of wood are needed to create the thick floors required for these structures, so it is generally bulkier than other alternatives. Wood is also flammable, more prone to moisture-induced decay, and more susceptible to termite infestation in humid conditions than other more resilient materials like concrete.

Another building material commonly found in modern structures is a metal deck (Fig. 3). Also known as corrugated metal, it is resistant to heat, natural disasters, and depending on its thickness and the type of metal used, it can be relatively lightweight compared to wood or concrete. The metal deck is also extremely durable and requires less upkeep than other roofing methods and is safer because it is not flammable $[2,3]$.

The metal deck also has disadvantages, such as being prone to rust when exposed to moisture and requiring 

Single or Multiple Family Dwellings' Flooring Systems

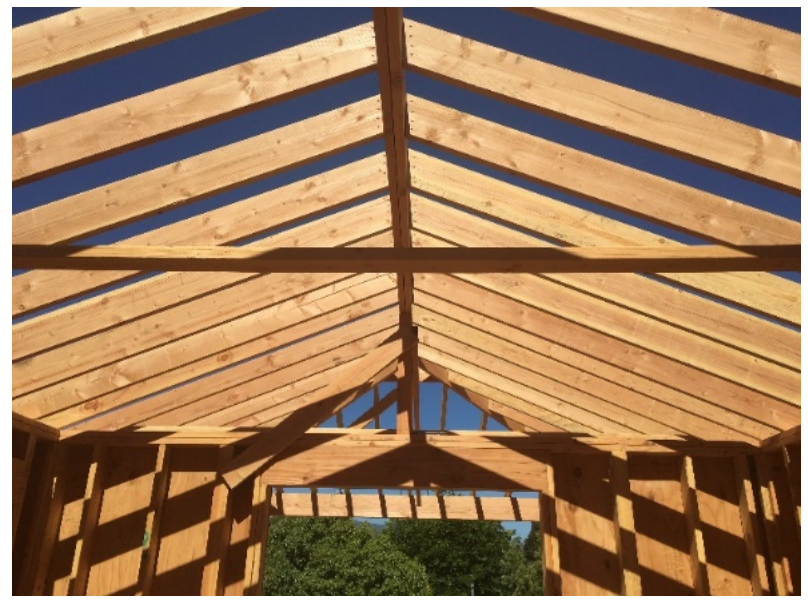

Fig. 1 Wood beams.

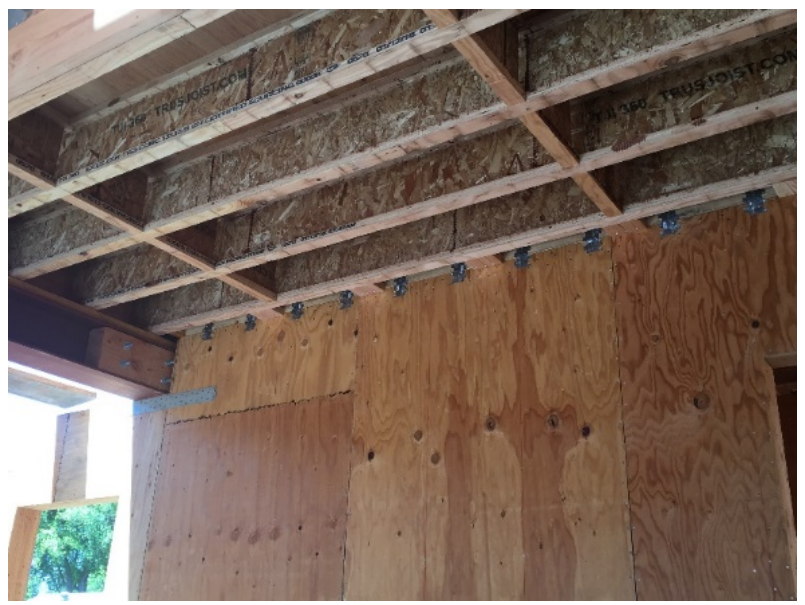

Fig. 2 Wood joists.

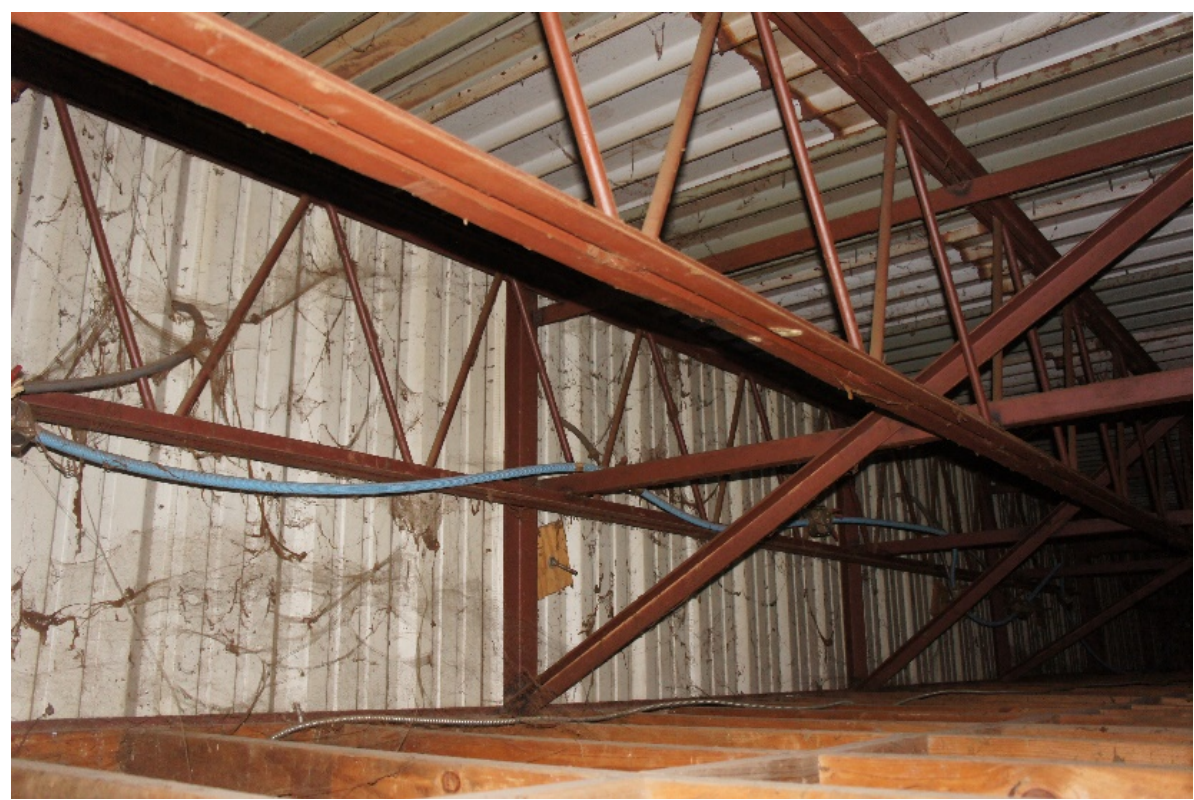

Fig. 3 Metal deck. 
specialized tools in order to be used properly. Also, in many areas, the metal deck is harder to find and more expensive to build with than a comparable material such as wood. Although this deck is typically effective in larger structures, it generally needs to be cut and covered with concrete to be effective, which makes it costly and ineffective in smaller residential applications.

However, by utilizing a new technique, it is possible to create flooring suited for residential areas, which combines the benefits of wood and metal deck. This new flooring is made from inverted $U$ sections (IUS) covered with sheathing and has many of the ideal qualities sought after for a practical residential floor such as resilience, ease of installation, and cost-effectiveness. By using IUS as a foundation in conjunction with a composite concrete sheathing poured around it, a thin, sturdy, and practical walking surface can be created (Fig. 4).

This surface is cost-effective in residential structures as well as durable and long-lasting. While there are similar products on the market, such as hat section metal deck, these U sections utilize a unique shape and are easier to use in residential applications because they use discrete parts. Hat section [4], metal deck, which has a similar shape to these inverted U sections $[5,6]$, but is typically connected in large sheets, which makes it challenging to work with, and requires a heavy concrete layer to be effective. The $U$ section is unlike anything on the market, its design gives it strength and versatility that other products do not possess, and it is more cost-effective than a traditional metal deck. This efficacy of this flooring also becomes more promising if new methods to obtain cheap metal become available in the future, which might be possible with new business ventures such as recycling.

\section{Test Set Up}

A testing platform was built to test the IUS sections. The testing platform has two supports that are $1 \mathrm{~m}$ wide and $1 \mathrm{~m}$ tall. These supports are made of HSS $180 \times 70$ $\times 5 \mathrm{~mm}$ and two IPE 240 as the tested beams are then used to connect the supports. IPE 240 has significantly higher stiffness that the IUS sections, so the deflection of the IPE will not affect the answers. The supports were also connected with two $40 \times 40 \mathrm{~mm}$ anchors to prevent sliding and movement on the ground.

The first IUS profile was placed on the testing platform support, and the four edges of the section are welded to the platform to prevent sliding. Then, all other sections were placed with $34 \mathrm{~mm}$ on the center to create the expected model of the deck.

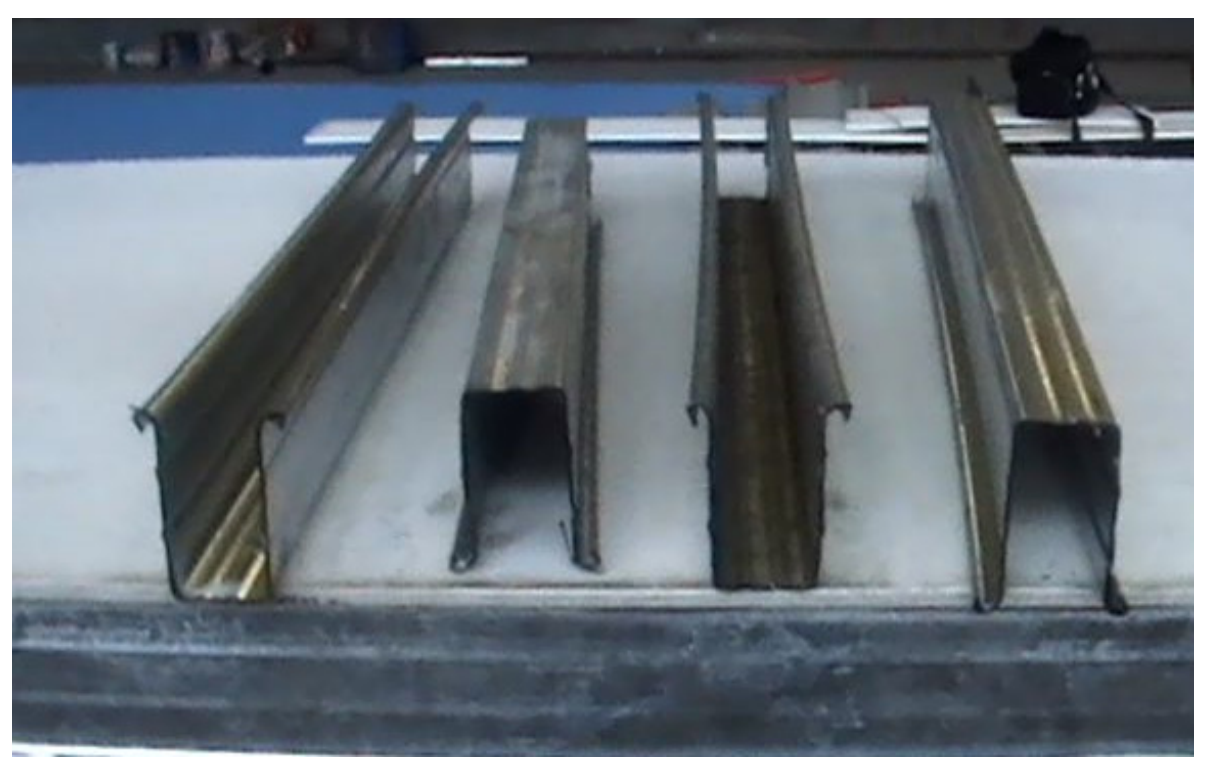

Fig. 4 The individual inverted U-channel sections. 
After placement completion, the edges of all the IUS sections were welded to the support. Finally, the typical sheathing (1/2") was placed on top of the sections and connected to the IUS profiles with TEK screws (Fig. 5).

A thin $100 \times 50 \mathrm{~mm}$ strip is then welded to the bottom of the channels to measure the deflection that occurs in the middle of the beam. This strip is placed parallel to the supports and $2.5 \mathrm{~m}$ from each respective support. An indicator clock is connected to this strip and tared so that both pointers start at zero (Fig. 6).

The model is loaded with $8 \mathrm{~kg}$ steel sheets $(2 \times 1 \mathrm{~m})$ to ensure even distribution of the load (Fig. 4). Initially,
18 sheets weighing $1,521 \mathrm{~N} / 5 \mathrm{~m}^{2}$ are placed on the model, and resulting deflection is recorded with indicator clock. Then, in each subsequent stage, 18 additional layers are added to the previous load, and the resulting deflection is measured. This is repeated until $q_{\max }$ is achieved $\left(1,507 \mathrm{~N} / \mathrm{m}^{2}\right.$ (96 sheets)), and the deflection matches the maximum allowed value of 1.39 cm (Figs. 7 and 8).

\section{Material Specification}

The dimensions of the IUS channel are $102 \times 54 \times$ $10 \times 12 \times 1 \mathrm{~cm}$ as specified following the model $\mathrm{A} \times \mathrm{B}$ $\times \mathrm{d} 1 \times \mathrm{d} 2 \times \mathrm{t}$, as defined in Fig. 9 and Table 1 [7].

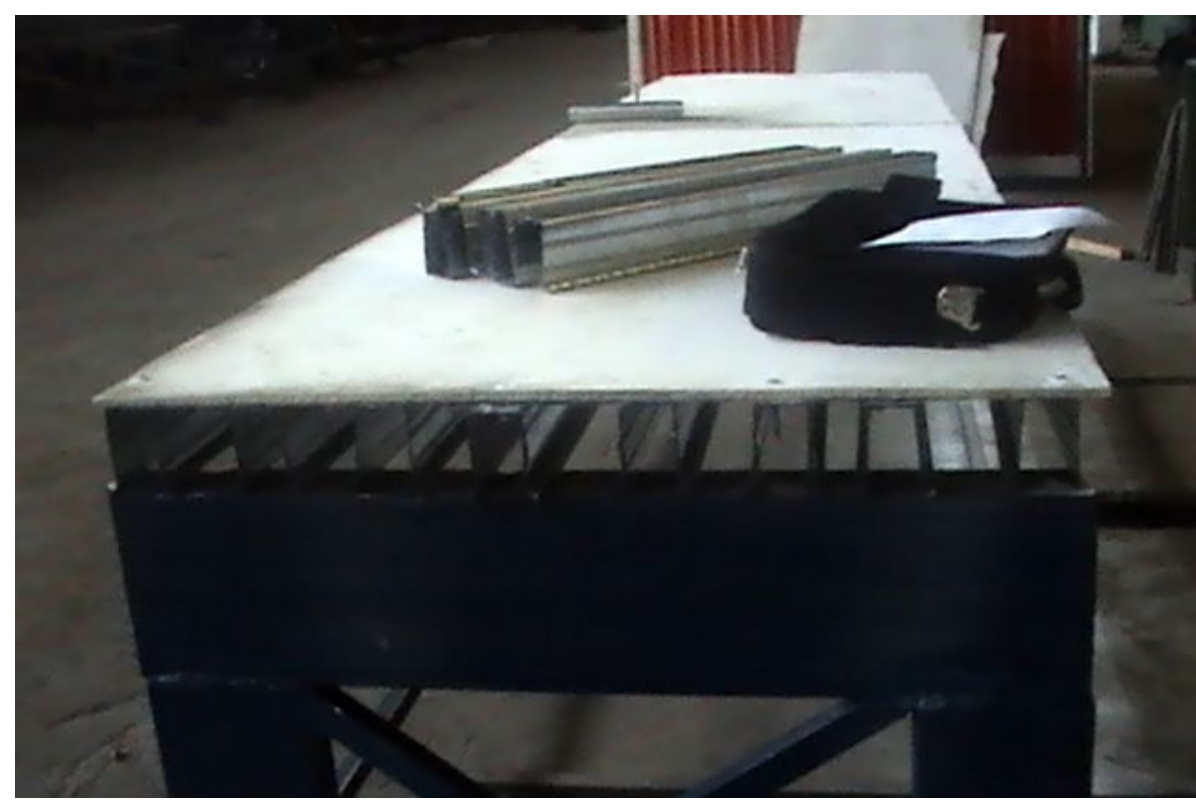

Fig. 5 The IUS profile segments welded together on the testing rig viewed from the side.
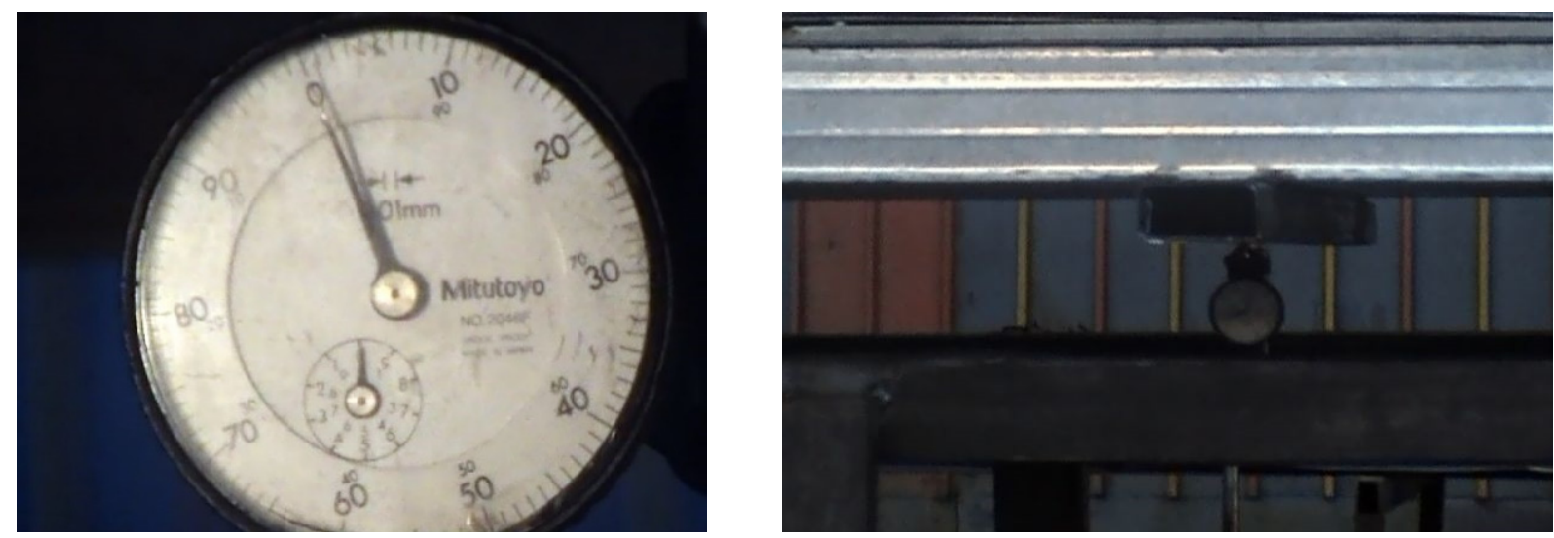

Fig. 6 The indicator clock zeroed out underneath the middle of the beam of the testing rig. 
Numerical and Experimental Evaluation of New Cold form Inverted "U" Section in Single or Multiple Family Dwellings' Flooring Systems

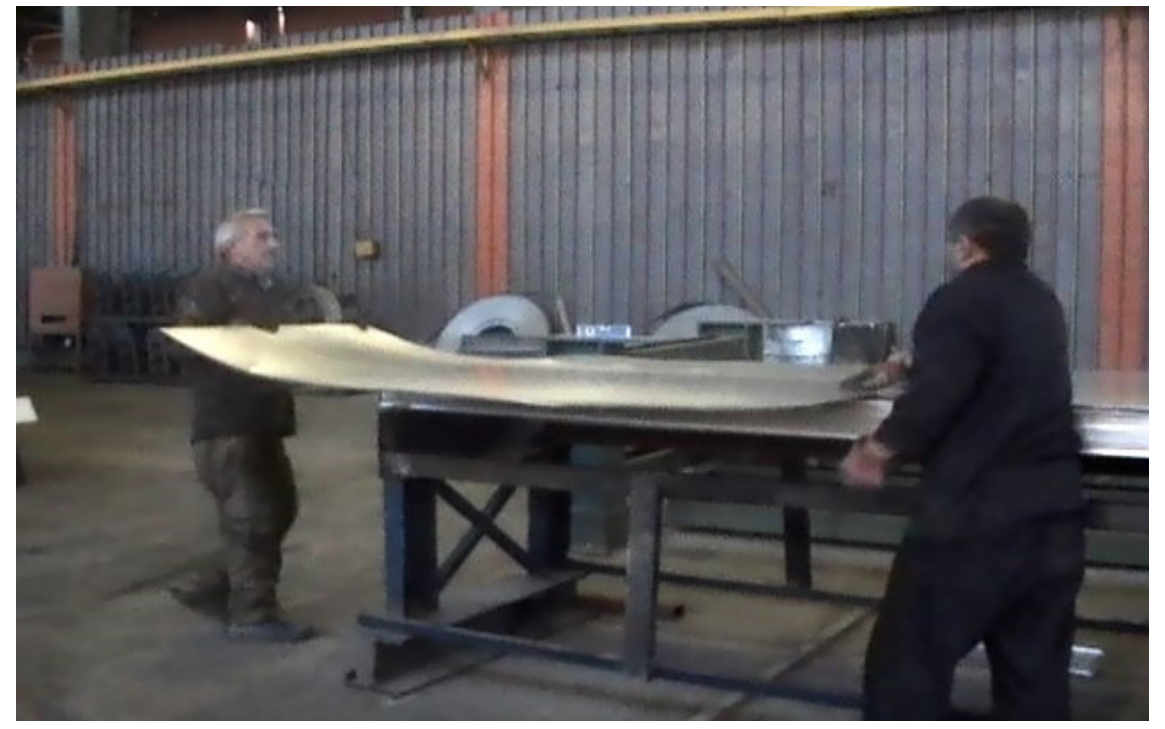

Fig. 7 A floor sheathing being carefully placed on top of the beam testing rig to begin the experiment.

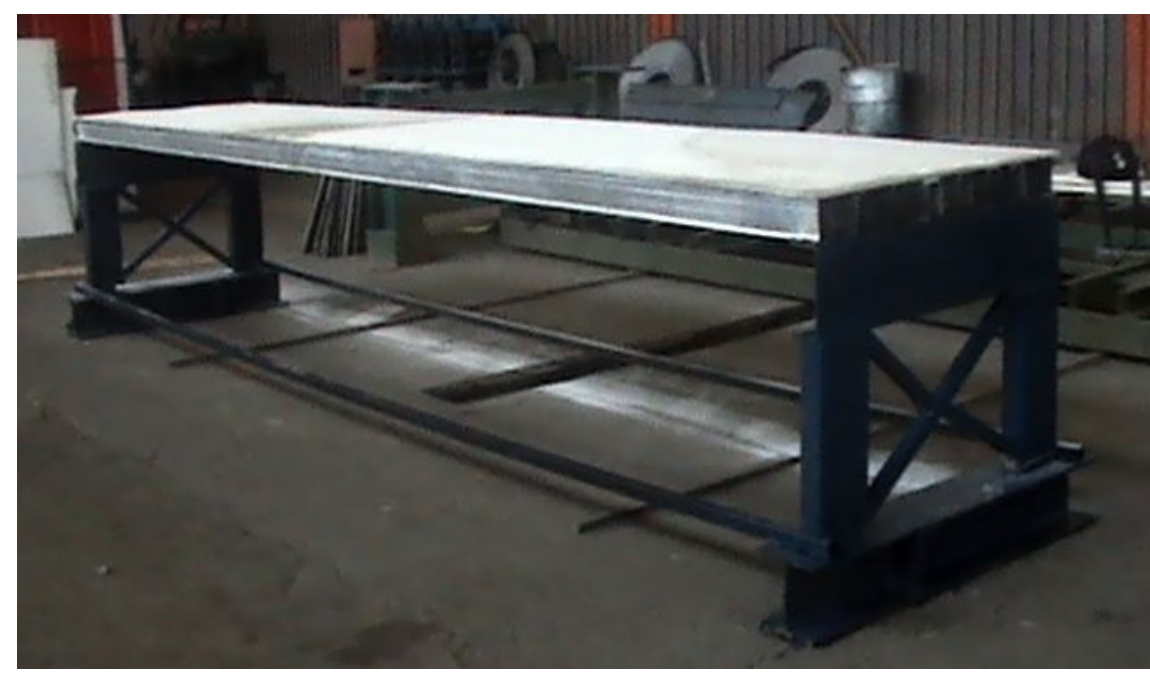

Fig. 8 A view of the IUS test frame; sheathing was placed on top.

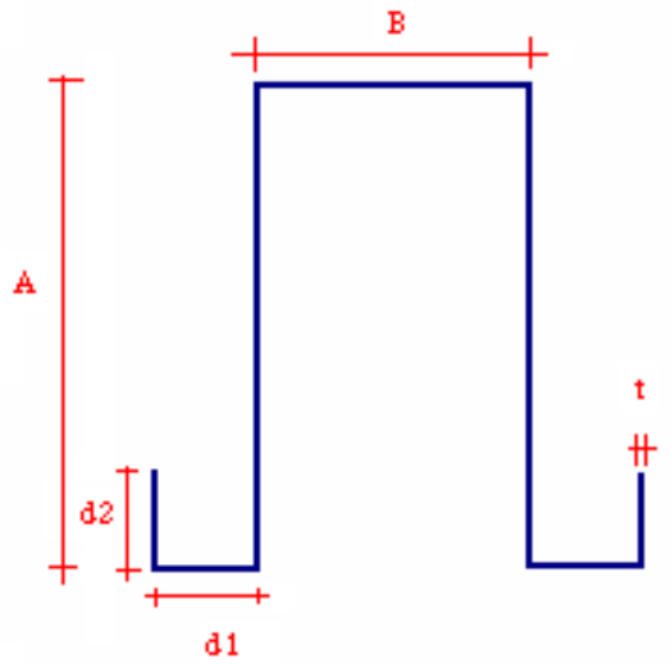

Fig. 9 IUS channel dimensions. 
Table 1 IUS channel dimensions.

\begin{tabular}{lllll}
\hline $\mathrm{A}(\mathrm{cm})$ & $\mathrm{B}(\mathrm{cm})$ & $\mathrm{d} 1(\mathrm{~cm})$ & $\mathrm{d} 2(\mathrm{~cm})$ & $\mathrm{t}(\mathrm{cm})$ \\
\hline 102 & 54 & 10 & 12 & 1 \\
\hline
\end{tabular}

Table 2 Detailed material specifications.

\begin{tabular}{|c|c|c|c|c|c|c|c|c|c|}
\hline $\begin{array}{l}\text { Area } \\
\left(\mathrm{cm}^{2}\right)\end{array}$ & $\begin{array}{l}\mathrm{I}_{\mathrm{xx}} \\
\left(\mathrm{cm}^{4}\right)\end{array}$ & $\begin{array}{l}\mathrm{I}_{\mathrm{yy}} \\
\left(\mathrm{cm}^{4}\right)\end{array}$ & $\begin{array}{c}\mathrm{S}_{\mathrm{xx}}(\mathrm{top}) \\
\left(\mathrm{cm}^{3}\right)\end{array}$ & $\begin{array}{c}\mathrm{S}_{\mathrm{xx}}(\text { bottom }) \\
\left(\mathrm{cm}^{3}\right)\end{array}$ & $\begin{array}{c}\mathrm{S}_{\mathrm{yy}}(\text { right }) \\
\left(\mathrm{cm}^{3}\right)\end{array}$ & $\begin{array}{c}\mathrm{S}_{\mathrm{yy}}(\mathrm{left}) \\
\left(\mathrm{cm}^{3}\right)\end{array}$ & $\begin{array}{l}X_{\mathrm{cg}} \\
(\mathrm{cm})\end{array}$ & $\begin{array}{l}Y_{\mathrm{cg}} \\
(\mathrm{cm})\end{array}$ & $\begin{array}{l}\text { Weight } \\
(\mathrm{kg} / \mathrm{m})\end{array}$ \\
\hline 3 & 41.2797 & 20.6356 & 8.363 & 7.6957 & 5.5772 & 5.5772 & -5.10 E-17 & 0.164 & 1.627 \\
\hline
\end{tabular}

The center of the surface of the IUS section is calculated with a $1 \mathrm{~mm}$ sheet on it $(y=6.45 \mathrm{~cm})$, and the moment of inertia is calculated in relation to the previous measurement $\left(I=5.98 \mathrm{~cm}^{4}\right)$. The profile section modulus can be obtained by using the formula:

$$
S=\frac{I}{Y}
$$

With the section modulus and the relationship:

$$
S=\frac{M_{M A X}}{F_{B}}
$$

Given that $F_{y}=240 \mathrm{MPa}, F_{B}=0.6, F_{Y}=144 \mathrm{MPa}$, and $E=210,000 \mathrm{MPa}$. More advanced material specifications are included in Table 2.

The centroid of the section is located at $(-5.10 \mathrm{E}-17$, $0.164) \mathrm{cm} . \mathrm{I}_{\mathrm{xx}}$ is the moment of inertia about the $\mathrm{x}$-axis of the centroid, and $\mathrm{I}_{\mathrm{yy}}$ is the moment of inertia about the $\mathrm{y}$-axis of the centroid. $\mathrm{S}_{\mathrm{xx}}$ (top) is the section modulus of the channel above the $\mathrm{x}$-axis, $\mathrm{S}_{\mathrm{xx}}$ (bottom) is the section modulus of the channel below the $\mathrm{x}$-axis, $\mathrm{S}_{\mathrm{yy}}$ (right) is the section modulus for the part of the channel to the right of the $y$-axis, and $S_{y y}$ (left) is the section modulus for the part of the channel to the left of the $y$-axis.

\section{Numerical Evaluation}

$M_{\max }$ is calculated as $\left(M_{\max }=1,226.17 \mathrm{~N} / \mathrm{m}\right)$. The existing beam has an extensive load with simple final supports which can be represented by the equation:

$$
M_{\max } \text { (at center) . . . . . . . }=\frac{w \ell^{2}}{8}
$$

where $w$ is the load per unit length and $l$ length of the beam. Given that $w_{1}=3.86 \mathrm{~N} / \mathrm{m}$ and that deflection is controlled according to the relationship that:

$$
\Delta_{\max }(\text { at center }) \quad . . . . .=\frac{5 w \ell^{4}}{384 E I}(4)
$$

where $E$ is the modulus of elasticity, and $I$ is the moment of inertia. This deflection must be less than the allowed value of $\mathrm{L} / 360$. According to the obtained $w_{1}$ value, this was not the case $(\Delta=2.9 \mathrm{~cm}>\Delta$ allowable $=1.39 \mathrm{~cm})$. This means that $w$ must be calculated in a way that the deflection level $(I)$ does not exceed the allowed level. Therefore, the maximum deflection, $w_{\max }$, is estimated to be $187.57 \mathrm{~N} / \mathrm{m}$. Since $w_{\max }$ is lower than the previous $w$ value, this section modulus is acceptable. Table 3 shows calculations based on different loading scenarios using the calculated quantities.

\section{Tests' Results and Verification}

When the load is increased, the sample remained intact, but the deformation sustained by the beam changes from elastic to plastic deformation. This means that when the load is removed there is permanent deformation, and the beam will not return to its original unloaded state. Nonetheless, the load sample was increased up to a value of $1,883.5 \mathrm{~N} / \mathrm{m}^{2}$, and the deflection value shows it did not fracture, confirming its durability. The values of deflection observed from the different loading stages are recorded in Table 4 alongside the values for the calculated quantities of deflection. To provide realistic results, team members ran and jumped over the roof multiple times before and after testing so the model would be more subjected to the realistic application. Finally, time was taken between loading and testing the 

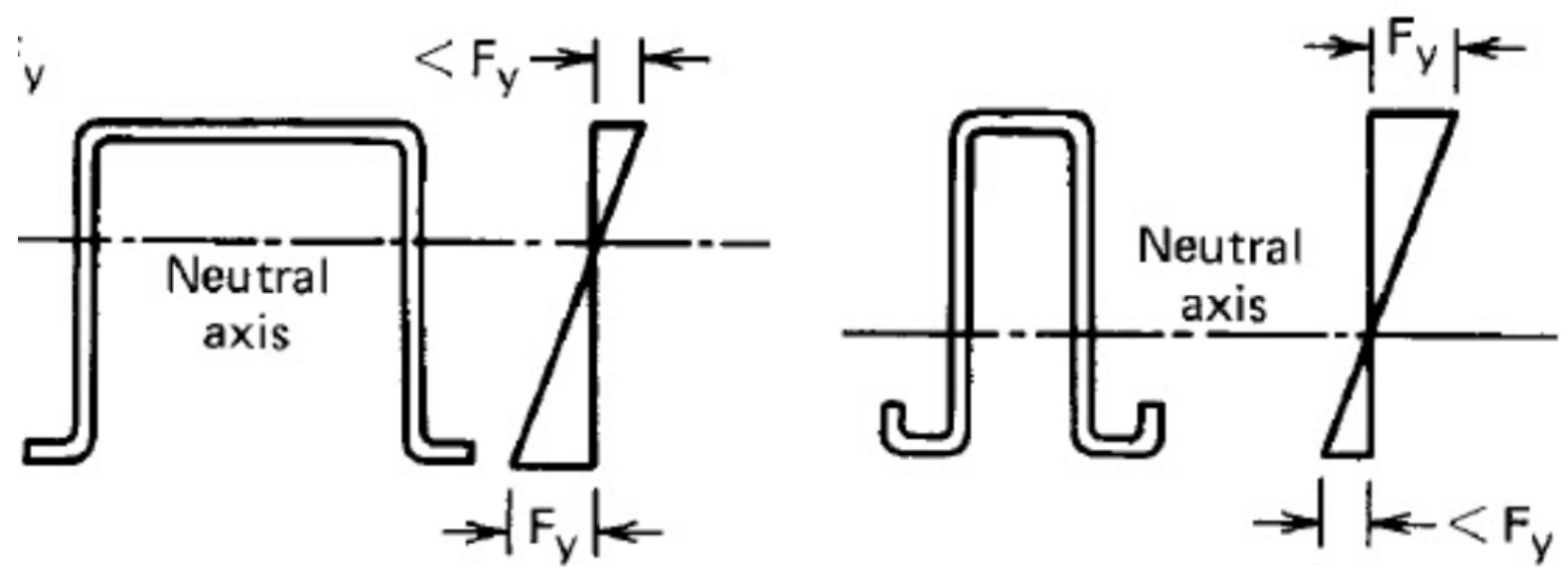

Fig. 9 Theoretical behavior of $U$ sections.

Table 3 Result obtained from the analysis of the roof made of IUS profile.

\begin{tabular}{|c|c|c|c|c|c|c|c|c|c|c|}
\hline $\begin{array}{l}\text { Beam length } \\
\text { (cm) }\end{array}$ & $\begin{array}{l}M \\
(\mathrm{~N} \cdot \mathrm{m})\end{array}$ & $\begin{array}{l}\text { Required } \\
\text { Sx }\left(\mathrm{cm}^{3}\right)\end{array}$ & Section & $\mathrm{Sx}\left(\mathrm{cm}^{3}\right)$ & $I\left(\mathrm{~cm}^{4}\right)$ & $\begin{array}{l}\Delta 5 w l^{4} / E I \\
(\mathrm{~cm})\end{array}$ & $\begin{array}{l}\Delta \text { all }(\mathrm{cm}) \\
\mathrm{L} / 360\end{array}$ & $Q\left(\mathrm{~kg} / \mathrm{m}^{2}\right)$ & $w$ distributed & $\begin{array}{l}\text { Number of } \\
\text { sheets }\end{array}$ \\
\hline 500 & 153.0 & 1.08 & $\begin{array}{l}\mathrm{U} 102 * 54 * 10 * 1 \\
2 * 1+\mathrm{PL} 1\end{array}$ & 8.68 & 55.98 & .36 & 1.39 & 40 & 150 & 6 \\
\hline 500 & 307.1 & 2.17 & $\begin{array}{l}\mathrm{U} 102 * 54 * 10 * 1 \\
2 * 1+\mathrm{PL} 1\end{array}$ & 8.68 & 55.98 & .72 & 1.39 & 80 & 300 & 12 \\
\hline 500 & 407.1 & 2.89 & $\begin{array}{l}\mathrm{U} 102 * 54 * 10 * 1 \\
2 * 1+\mathrm{PL} 1\end{array}$ & 8.68 & 55.98 & .97 & 1.39 & 106.66 & 400 & 16 \\
\hline 500 & 512.7 & 3.62 & $\begin{array}{l}\mathrm{U} 102 * 54 * 10 * 1 \\
2 * 1+\mathrm{PL} 1\end{array}$ & 8.68 & 55.98 & 1.21 & 1.39 & 133.33 & 500 & 20 \\
\hline 500 & 582.7 & 4.13 & $\begin{array}{l}\mathrm{U} 102 * 54 * 10 * 1 \\
2 * 1+\mathrm{PL} 1\end{array}$ & 8.68 & 55.98 & 1.38 & 1.39 & 152 & 570 & 23 \\
\hline
\end{tabular}

Table 4 Observed results of loading compared to established laboratory values.

\begin{tabular}{llllllllll}
\hline $\begin{array}{l}\text { Test } \\
\text { steps }\end{array}$ & $w(\mathrm{~N} / \mathrm{m})$ & $\begin{array}{l}Q \text { Extensive } \\
\text { load }\left(\mathrm{N} / \mathrm{m}^{2}\right)\end{array}$ & $\begin{array}{l}\Delta \text { Calculated } \\
\text { deflection }(\mathrm{cm})\end{array}$ & $\begin{array}{l}\Delta \text { Measured } \\
\text { observed } \\
\text { deflection }(\mathrm{cm})\end{array}$ & $\begin{array}{l}\Delta \text { Maximum } \\
\text { allowable } \\
\text { deflection }(\mathrm{cm})\end{array}$ & $\begin{array}{l}\text { Number } \\
\text { of sheets each sheet } \\
\text { used }\end{array}$ & $\begin{array}{l}\text { Error } \\
\text { deflection } \\
(\%)\end{array}$ & $\begin{array}{l}\text { Weight per } \\
\mathrm{m}^{2}(\mathrm{kN} / \mathrm{m})\end{array}$ \\
\hline 1 & 35.32 & 282.53 & 0.26 & 0.204 & 1.39 & 18 & 8 & $\pm 27.45 \%$ & 0.7063 \\
2 & 70.63 & 565.06 & 0.523 & 0.484 & 1.39 & 36 & 8 & $\pm 8.058 \%$ & 1.413 \\
3 & 100.06 & 800.50 & 0.74 & 0.747 & 1.39 & 51 & 8 & $\pm 0.937 \%$ & 2.0012 \\
4 & 123.61 & 988.85 & 0.915 & 0.92 & 1.36 & 63 & 8 & $\pm 0.546 \%$ & 2.4721 \\
5 & 135.38 & 1083.02 & 1.003 & 1.013 & 1.39 & 69 & 8 & $\pm 0.997 \%$ & 2.7076 \\
6 & 141.12 & 1130.11 & 1.046 & 1.056 & 1.39 & 72 & 8 & $\pm 0.956 \%$ & 2.8523 \\
7 & 158.92 & 1271.38 & 1.17 & 1.193 & 1.39 & 81 & 8 & $\pm 1.966 \%$ & 3.1392 \\
8 & 164.81 & 1318.46 & 1.22 & 1.235 & 1.39 & 84 & 8 & $\pm 1.230 \%$ & 3.2962 \\
9 & 176.58 & 1412.64 & 1.308 & 1.321 & 1.39 & 90 & 8 & $\pm 0.994 \%$ & 3.5316 \\
10 & 188.35 & 1506.82 & 1.395 & 1.408 & 1.39 & 96 & 8 & $\pm 0.932 \%$ & 3.7670 \\
11 & 200.12 & 1600.99 & 1.49 & 1.492 & 1.39 & 102 & 8 & $\pm 0.134 \%$ & 4.0025 \\
12 & 235.44 & 1883.52 & 1.74 & 1.749 & 1.39 & 120 & 8 & $\pm 0.517 \%$ & 4.7088 \\
\hline
\end{tabular}

deflection of the flooring to allow the floor to reach its maximum deflection and mitigate error. Fig. 10 shows the comparison between the calculated deflection and the tests' results.

\section{Comparison to Similar Materials}

Using the results from the experiment to perform a price to length analysis, it shows that the inverted $\mathrm{U}$ section could be a promising alternative to traditional 
residential flooring techniques (Fig. 11). Compared to metal deck, the $U$ sections flooring is significantly cheaper and more versatile while retaining comparable strength and material properties. Similarly, at lengths under $18 \mathrm{ft}$, $\mathrm{U}$ section flooring is less expensive than natural wood beams (with rectangular section) and has increased strength, durability, and overall resilience. While engineered wood joists (with I section) are slightly cheaper per square foot than the $U$ section flooring for the longer length (15' and more), U section flooring can be utilized at smaller lengths and are stronger and more durable than both natural and engineered wood joists, which still makes it a competitive alternative. This inverted $U$ section flooring is also non-flammable and can create thinner floors than both wood beams and joists. Although more work must be done in infrastructure and installation techniques, our initial findings show $U$ section flooring to be a promising alternative to traditional flooring materials in residential applications.

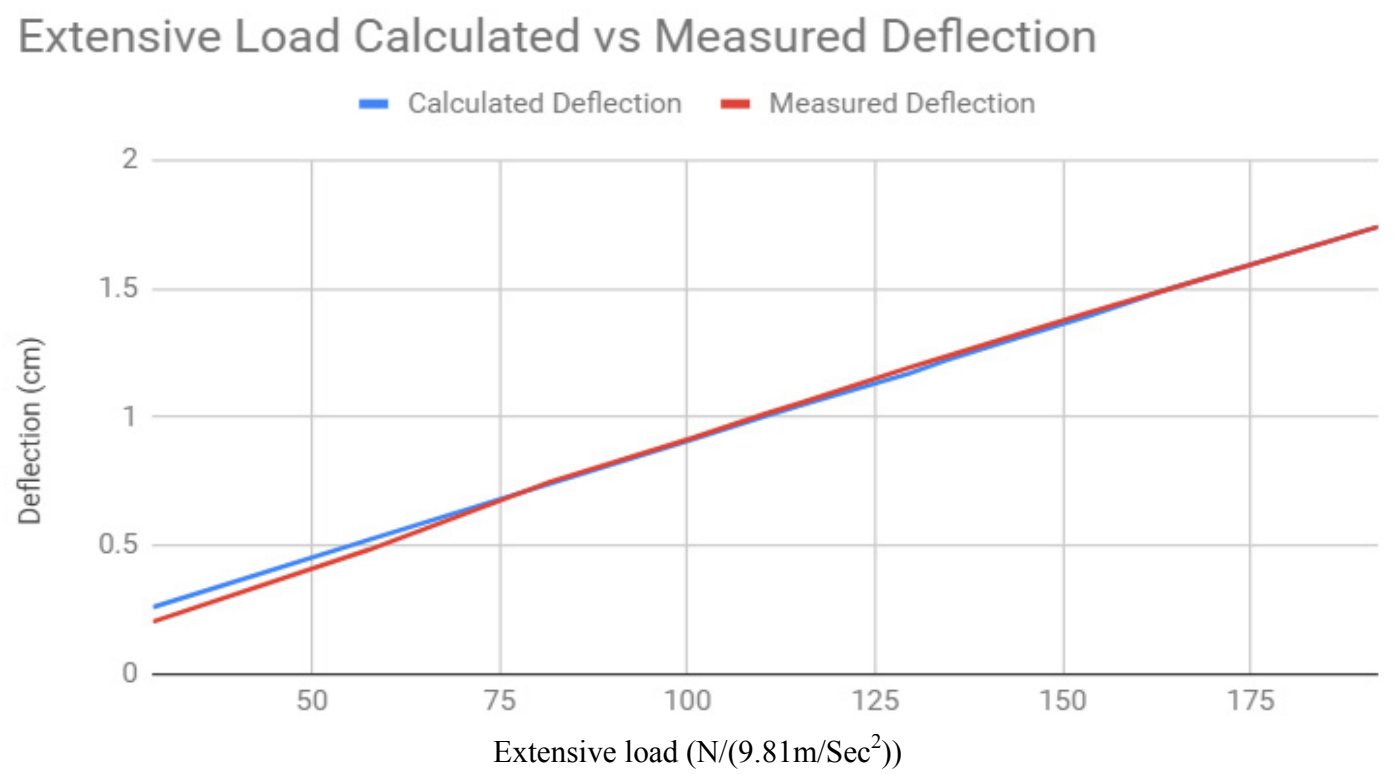

Fig. 10 A line graph comparing the similarity between the calculated and measured deflection values observed during the test.

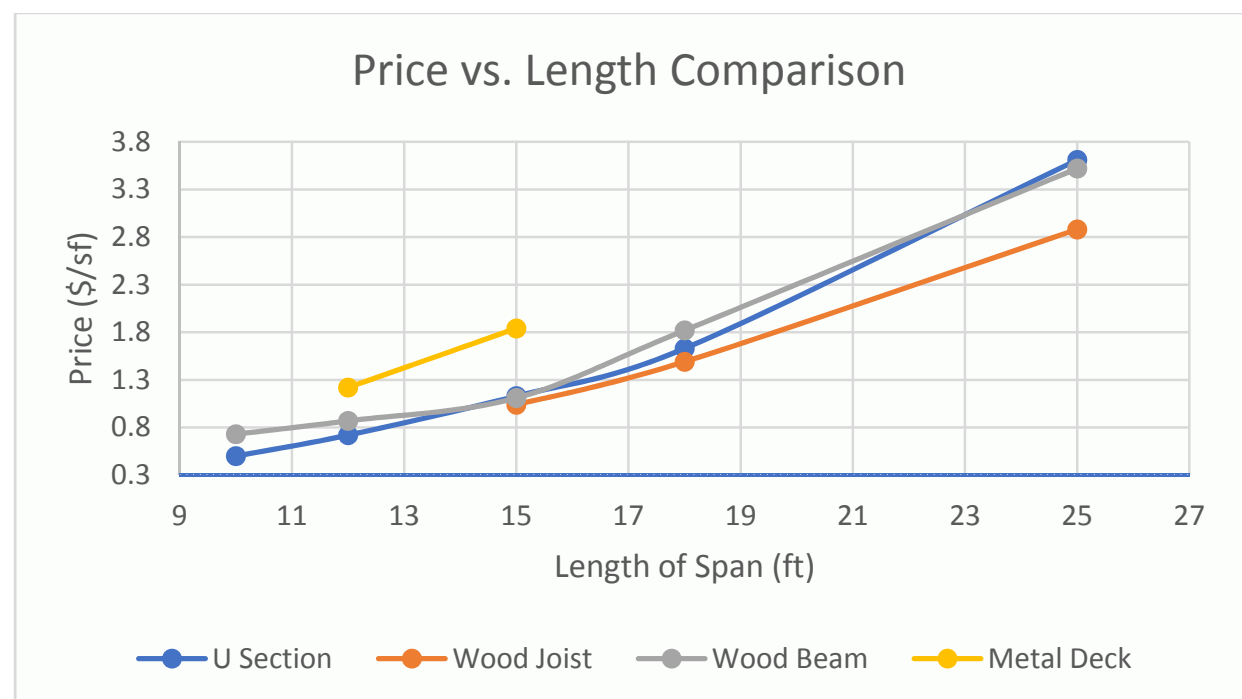

Fig. 11 Price vs. length analysis of different materials* (wood joist is referred to engineered wood with I section and wood beam is referred to natural wood lumber with rectangular section).

* The price in US dollar and it is based on the market in the US and Silicon Valley 2019. 


\section{Conclusion}

This article introduced flooring created from cold-formed inverted $\mathrm{U}$ section and a plaster layer and tested its efficacy for residential applications. The performance of this floor was tested by loading a model floor with a variety of different loads and observing the reflection the floor experienced using an indicator clock. This process was repeated until the sample floor reached the maximum allowable deflection value. Then, the data were then compared to theoretical results to see if the outcome was consistent and predictable. Finally, this material was compared to similar materials to determine its commercial viability. Results show:

- The results were consistent with the theoretical model, as shown in Tables 1, 2, and Fig. 10.

- When the reflection reaches its maximum value allowed, no change was observed in the associated structural components (bolts and rivets) of the flooring.

- Based on the price to length analysis, cold-formed inverted $U$ section can be produced more cheaply than the metal deck and retain similar material properties.

- The comparison of the prices shows that IUS is a good alternative for both natural and engineered wood joists and metal deck system with a span of less than 25 , and the best for the spans up to 15' (Fig. 11).

- The height of the floor for the span up to $25^{\prime}$ is about 4"-6" while for the use of wood joists it is between 6"-12".

- Cold-formed inverted U section have comparable costs to natural wood beams and engineered joists with
I section and make up for any disparities with superior strength, durability, and corrosion resistance.

- Although there are similar products (such as a metal deck) to the cold-formed inverted $U$ section that were tested, the $\mathrm{U}$ section is unique to what is on the market today.

\section{Acknowledgments}

This project was conducted under the request of the ISP group to verify the efficiency of the newly designed section. The tests were conducted with test facilities at the ISP factory. The research on the application was conducted at Santa Clara University.

\section{References}

[1] Building and Construction Technology, UMass Amherst. 2019. "The Evolution of Engineered Wood I-Joists." https://bct.eco.umass.edu/publications/articles/the-evoluti on-of engineered-wood-i-joists/.

[2] ASC Steel Deck. 2018. Roof Deck Catalog. Version 2.0. ASC Profiles LLC.

[3] Writer, S. F. 2019. "Pros and Cons of Metal Roofs for Your Home.” https://www.statefarm.com/simple-insights/ smart-ideas/wondering-about-metal-roofs-here-are-the-pr os-and-cons.

[4] American Iron and Steel Institute. 2003. "AISI-Specifications for the Design of Cold-Formed Steel Structural Members." In AISI Manual Cold-Formed Steel Design 2002 Edition, 130.

[5] BlueScope Lysaght. 2010. Cold Formed Sections. BlueScope Steel Limited.

[6] Ware Industries. 2014. Cold Formed Structural Framing Systems.

[7] Ghafooripour, A., Saghafi, H., and Rezapoor, M. R. 2007. "Full-Scale Tests of Floor Using Cold from Chanel CT100." Gostaresh Sakhteman Journal (14). 